\title{
Higher Education - from Global trends to Local realities
}

\section{Overview}

We live in the age of globalisation. But what does this mean, and what are the implications for universities? As we see accelerations in the movement of people, resources and ideas, universities are caught up in globalisation and also contribute to the process itself. At one level it is possible to discern worldwide trends around an increase in the numbers of students and then graduates, how this and research are funded, and how universities are managed. Universities and university sectors are becoming more similar in some ways but it would be a mistake to think that they are (or will ever be) identical. 'Below' the global, we have the regional, national, and local dimensions, and each of these is crucial in considering what life for - and in universities might be like.

The structure of this chapter is as follows: Firstly, it will look at globalisation as a phenomenon before considering how it relates to higher education, which involves involve an outline of global shifts in university policy. Dynamics at the regional level will then be considered before we examine how these trends play out in practice in Germany and England. This will provide the background against which we can delve a little deeper into what it might be like to be a student in each country. The answer is, of course, the same but different.

\section{Globalisation}

Globalisation has been neatly summarised as a 'compression of space, time and meaning' (Alexander 2005, p.82). In other words, as technology allows people, information, and resources to traverse the globe in shorter periods of time, we have become increasingly connected to one another. We can fly half way round the world in just over 24 hours, send instantly received text messages and email, or video chat, with people anywhere in the world, something that twenty years ago was in the realms of science fiction. We can also see news unfolding around the world in real time and transfer money in moments. This brings distant people and interactions into what can be an immediate proximity with one another, and the reduction in distance has a number of important effects.

Firstly, we come to share more information, ideas, and even values - this constitutes the compression of meaning. As Simon Marginson (2011) describes, we are coming to 'synchronise' globally because we are aware of globalisation and have developed a sense of being connected to other people, places, and phenomena. This comes about through a greater awareness of other people's lives on social and other media, enabling us to feel connected to them and issues such as global warming or armed conflicts that lead to 
Do not cite without author's permission.

refugees or even imported terrorism in our communities. At the same time as synchronising, as Marginson describes, we 'desever', feeling distant places to be closer than before. Over time, as we travel virtually and in person, meeting people from other places and sharing ideas, we develop better understandings of one other. Overall, this generates a sense of being less isolated, more interconnected, and moving to a shared global rhythm.

A second important effect of globalisation is that countries and organisations are more interdependent. Comparative education researchers have long been critical of 'methodological nationalism' (Dale 2005), an assumption that countries are ideationally and legislatively discrete. People and ideas have always travelled, and significant events in once place are affected by, and in turn affect, events elsewhere. What has changed is that the connections are faster and more frequent - they are constant. Those who make local and national policy must therefore increasingly do so with an eye on the broader picture, sometimes in rapid reaction to developments elsewhere in the world, and often in consultation with others outside their national jurisdictions. They have to make allowances around overarching rules and conventions frameworks on international law, human rights, and trade or environmental agreements. This brings in the need for collaboration between countries or groups of countries, often through supranational 'global governance institutions' (Buchanan \& Keohane 2011) such the World Trade Organisation (WTO) or between and within multi-country alliances such as the European Union (EU).

This observation connects to a final, crucial point, which is that globalisation is not simply a phenomenon emerging from technological progress. We must, of course, acknowledge the 'bottom up' effect of billions of individual interactions and reactions that is changing the way we think of ourselves and act. However, we also need to consider the 'top-down' side of the equation. When we look at this issue in the context of globalisation, it is important to recognise that global governance institutions may not be operating as neutral intermediaries but may themselves be powerful policy actors with political agendas (Robertson 2012). The influence can be direct, such as the conditions that organisations like the International Monetary Fund (IMF) impose with development loans such as enforced austerity or privatising state industries (Dreher et al. 2015). A less direct form is through international comparative exercises such as the OECD Programme for International Assessment (PISA) programme. When the results are published, policy-makers in 'weaker' countries feel impelled to divert resources to remedy supposed shortcomings in their national education systems (Meyer \& Benavot 2015). So while globalisation offers us the chance to share experiences and ideas, it also presents an opportunity for those with less altruistic intentions, particularly at the apex of power, to promote their own interests. 
Working Paper: Draft Chapter for

International and Comparative Education: Contemporary Issues and Debates.

Bartram, B. (Ed) Routledge Education Studies series.

Do not cite without author's permission.

\section{Globalisation and The University}

\section{Globally Connected Universities}

Universities have always been international, with scholars moving between countries, and research findings and ideas being shared widely. We can see synchronism in action as academics and students are increasingly internationally mobile, electronic communication facilitates contact and collaboration, and research has become more accessible in online journal articles and reports. It is far easier to be aware of the latest findings in our fields; in fact it has become unacceptable not to be. Desevering has also become the norm, as an international - global - orientation is expected of universities and the people associated with them (King 2011). This, in part, is the cumulative effect of countless international interactions on the psyche of higher education, but the policy level also plays a not insignificant role.

\section{The Neoliberal Knowledge Economy}

Much of the analysis of higher education from the 1980s onwards has been associated in some way with the emergence of the 'neoliberal knowledge economy' as the dominant global policy trend.

Neoliberalism is a political ideology that adopts an economic logic, primarily (or even solely) considering situations from a financial perspective. It is a reductive approach that can ignore aspects such as social or cultural value in part because they are difficult to measure and can thus be convenient to ignore. Neoliberals view the public sector as inherently inefficient, with free markets as the way forward because rivals have to continually up their game to survive. Governments should therefore deregulate, making markets as unencumbered by red tape and legislation as possible and/or creating new markets by privatising public services. The counter-arguments to the neoliberal perspective are largely two-fold. Firstly, a lack of regulation opens up the system to abuse as some organisations or individuals can act in a way that serves their own interests regardless of the consequences on others particular if a few players dominate the market. The current economic crisis was partly caused by this as financial institutions inflated a housing price and loan bubble which eventually burst but made huge profits in the process (Kotz 2009). The second criticism is that markets are an inappropriate way of providing products or services that are essential to the functioning of society. We could argue that bananas or holidays are well suited to markets as people can survive without them, but if some people were excluded (i.e. could not afford) services such as the police, healthcare - or education - it would create significant social problems. In such cases, opponents of neoliberalism would argue, should be provided by the state and funded by taxation, because markets are exclusionary.

The concept of the 'knowledge economy' emerged in the 1960s when the seeds of globalisation as we know it today were sown. Falling transport costs saw manufacturing move away from wealthy countries, who grew increasingly concerned about their economic health as jobs and profits moved overseas. They envisioned a new future where they were the 'head' of the 
Working Paper: Draft Chapter for

International and Comparative Education: Contemporary Issues and Debates.

Bartram, B. (Ed) Routledge Education Studies series.

Do not cite without author's permission.

global order - doing the thinking and inventing - while the poorer countries constituted the 'body', producing the goods (Brown et al. 2011). Central to this was the principle that knowledge has commercial value and should be exploited for profit/competitive advantage. This in itself is not new - patents and copyrights have long existed to allow the founders of new technologies, medicines, and so on, a period to recoup their research costs and turn a profit. What was new was that this principle became applied to knowledge more generally and this became embedded in government policy. To follow this logic through, the best knowledge is that which can be used to gain a competitive advantage (i.e. generate profit) for individual organisations and/or national economies. The implication is that knowledge which cannot be exploited in this way has less purpose, or even none at all.

\section{Universities in the Knowledge Economy}

How universities are positioned within a knowledge economy can be drawn out in three interrelated ways: students, funding, and governance. We will now examine each in turn.

Neoliberalism appropriated a concept known as human capital theory, which assumes that the countries with the most highly skilled workers outperform their competitors, and furthermore, that those workers earn more because of their value to employers (Brown et al. 2011). It is therefore in the national interest to drive up the number of graduates. The number of people attending university has been growing since the 1950s for several reasons such as more people completing upper secondary education and a growing demand for graduates on the labour market (Williams \& Cochrane 2010). However, the number of students has skyrocketed since the 1990s, actively encouraged by governments buying into human capital theory. In the 35 OECD countries alone, 22\% of 25-64 year-olds had a degree in 1998, and by 2013 it was 34\% (OECD 2000; OECD 2015). To put this in perspective, it represents an increase of almost 80 million graduates in fifteen years.

This rise in student numbers creates a problem for governments that pay their students' study costs, but the presence of the so-called 'earnings premium' from a degree - i.e. graduates' higher salaries - provides a solution as it justifies the implementation of tuition fees. Universities in countries like the US have had fees for some time, particularly at private universities, but the overall trend is that more and more countries are implementing and/or raising them (Tilak 2015). This in itself creates other problems such as the potential exclusion of poorer groups from university, or the disappearance of degrees in less obviously lucrative subjects (such as those in the humanities and social sciences).

If we apply the same financial rationale to research, then STEM (Science, Technology, Engineering, Maths) subjects should attract more (or all) funding because they lend themselves more easily to competitive advantage and profit. It is, of course, the (neoliberal) logic of the market that the weakest perish, but weakness here is determined by economic gain, not value to social and/or cultural life (Codd 2005). The financial argument, though, is held by some to be the persuasive one, particularly in times of global recession and austerity. 
Working Paper: Draft Chapter for

International and Comparative Education: Contemporary Issues and Debates.

Bartram, B. (Ed) Routledge Education Studies series.

Do not cite without author's permission.

There are also signs that privately commissioned in research universities is on the rise as governments tighten their belts and encourage universities to seek other sources of funding. This reduces the strain on state budgets but returns us to the problem of favouring research allied with commercial gain at the expense of philanthropy. The picture seems, in the main, to point towards a fall in public funding and an increasing presence of private finance in higher education (OECD 2015).

The third significant area of change comes in the form of governance. We can divide this into external (i.e. government or other bodies) and internal (i.e. management). We have already seen how the OECD's PISA can trigger changes in school education policy, and it is in the process of conducting a global 'AHELO' (Assessment of Learning Outcomes in Higher Education) project. As with PISA, this has been criticised for developing generic standards that may be inappropriate to some countries but against which they will nevertheless be judged (Ashwin 2015). These comparative projects also reflect a neoliberal disposition towards measurement as a way of encouraging competition. We can see this in an increase in competitive bidding for research funding (Auranen \& Nieminen 2010), a form of resource allocation that tends to be dominated by a small number of strong universities, leaving the rest out in the cold. A more publicly visible way that competitive market environments are encouraged is through the implementation of rankings as universities focus on improving their position in relation to their peers (Hazelkorn 2008). This 'audit culture' is also transferred into universities as working practices are increasingly atomised and quantified (Shore 2010). The intention is to identify areas of weakness that can be addressed to maximise efficiency, but the measures are often based on 'proxy' measures that approximate what they are intended to capture. Student satisfaction, for example, is often held as a reflection of teaching quality, but there is a broad spectrum of factors that contribute to students' wellbeing, and many of these are unrelated to teaching.

\section{Summary}

The story so far has used a broad brush to describe the character and influence of the knowledge economy on higher education, and it is apparent that there are some tensions there. These have long existed, but the literature suggests that we are at a particular 'pinch point' now. What seems to be under threat is the university's role as a public institution as its functions and benefits are privatised and potentially excluded from the public (See Calhoun 2006 for a good overview of public "vs" private).

There are counter discourses and movements to a competitive, commercially oriented higher education model (see, for example Neary \& Saunders 2016). However, a broad consensus supports the view that the knowledge economy is the globally dominant one, and we can see neoliberal university policies implemented from Africa (Croché \& Charlier 2012) to Australia (Marginson 2006). This worldwide view is important because it gives us a real sense that there are globally connected trends playing out, rather than a case of countries operating entirely independent of each other. They are not; they are 
Working Paper: Draft Chapter for

International and Comparative Education: Contemporary Issues and Debates.

Bartram, B. (Ed) Routledge Education Studies series.

Do not cite without author's permission.

reacting to one another, in competition, in a knowledge arms race. It is also vital, though, to acknowledge that 'globalisation is local' (Douglass 2005) because while we can generalise without detail, the implementation and effect of policy is 'on the ground', in the practises and lives of organisations and people. Before we arrive at the national, though, it is necessary to briefly examine an intermediary level: the regional.

\section{The Regional (European) Dimension}

As mentioned earlier, supranational but 'sub' global alliances or blocs are formed to develop shared policies. Germany and England, the countries we will shortly examine in more detail, are both - at least at the time of press members of the EU and also the European Higher Education Area (EHEA).

The EHEA, created in 2010 through what became known as the 'Bologna Process', describes itself as a space in which 48 countries 'continuously adapt their higher education systems making them more compatible and strengthening their quality assurance mechanisms' (EHEA 2016). University systems in Europe at the end of the 1990s produced qualifications that followed one of three contrasting degree structures. This made graduating in one country and working in another problematic because university and professional qualifications were not easily transferred to others (Corbett 2006). The solution was for all countries to adopt the same 'Anglo' (BachelorMaster-Doctorate) degree system. This involved an enormous undertaking as most countries' universities, professional bodies, and domestic labour markets had to change in order to align across the EHEA. There was also a concern that the standard of degree provision varied considerably, and therefore a common approach to quality assurance was seen as important (Fried et al. 2006).

Outside these issues, what became increasingly apparent was that the establishment of a common European university space was a bold outwardfacing move to create a globally competitive zone for knowledge creation (Robertson 2009). Alongside the Bologna Process, the 'Lisbon Strategy' sought to 'turn the EU into the most competitive knowledge-based society...to increase productivity and [meet the] competitive pressures of a globalised economy' (European Commission 2014). This would be achieved through, among other things, opening up markets, cutting red tape, investment in human capital, and integrating financial markets, with the intention of maintaining Europe's international advantage in knowledge and innovation. Here we can see the EHEA as a strategic move to construct a global higher education hub to attract students, highly skilled workers, and funding. In other words, Europe was seeking to establish itself as a central player in the now familiar global knowledge economy.

\section{The National}

Now (at last) we can turn our attention to Germany and England. It should be noted that the focus here is primarily on England within the United Kingdom because of its particular tuition fee system, although at times the policies and available data make the UK and England indivisible from one another. As we 
Working Paper: Draft Chapter for

International and Comparative Education: Contemporary Issues and Debates.

Bartram, B. (Ed) Routledge Education Studies series.

Do not cite without author's permission.

have seen, both Germany and UK belong to some of the same political (EU) and higher education (EHEA) groups and (now) have similar degree structures. We can also discern in their university sectors those trends of more students, changes to funding, and new modes of governance. However, as we examine each of these areas in more depth, contrasts begin to emerge.

\section{Student Numbers}

While Germany has three main types of tertiary provider, we will chiefly concern ourselves with the 'Universität' as the more research-oriented of the three. There were 15 Universitäten in 1945, and now there are now over 150 (Hoschschulrektorkonferenz 2016). England had ten universities in 1945 and currently has 108 (HEFCE 2016). In line with the general trends described earlier, the number of students in both had risen steadily post World War II, and this resulted in a number of new universities being built in the 1960s and 70s (Teichler 2008; Mountford 1966). While in England the creation of new universities kept pace with the expansion in university entrants, demand for places in Germany began to fast outstrip their availability in the 1970s. A decision was made to increase the number of universities and also to allow them to admit more students than they had capacity for (Bloch 2009). Intended as a short-term measure to stop those with lower qualifications being squeezed out of vocational courses altogether, this is essentially still in place as student numbers have continued to increase. The 1990s trend of rapidly escalating student numbers was also repeated in both England and Germany, but it has been more marked in the former than the latter. Englishspecific figures are not available, but the proportion of people with a university education in the UK has risen from $26 \%$ to $42 \%$, while in Germany it has risen from $23 \%$ to $27 \%$ (OECD 2015). The way in which this has been funded has differed, as we will see.

\section{Funding}

The increase - beyond universities' capacity - in the number of students in Germany hugely overstretched institutional resources (Pritchard 2006). Tuition fees were not levied, and in 2002 the national government prohibiting their imposition by law. This was immediately and successfully contested as overstepping the jurisdictions of the individual federal states (Bundesländer) that constitute Germany. Seven of the 16 Bundesländer then imposed fees at around $€ 500$ a year, but over the next 12 years their local governments changed and tuition fees were revoked. In England, the story could not have been more different. Fees of up to $£ 1000$, dependent on parental income, were introduced a UK-wide basis in 1998, and in England they rose to $£ 3000$ in 2004 and then $£ 9000$ from 2012. Scotland abolished tuition fees for its students in 1999, and Wales and Northern Ireland subsidise their students somewhat. Both Germany and England saw public demonstrations against tuition fees at various points, but the chief difference is that there was political resistance in some political parties in Germany but very little in England.

The federal system in Germany also influences how its research is supported, with all universities being awarded 'primary funding' that covers their main 
International and Comparative Education: Contemporary Issues and Debates.

Bartram, B. (Ed) Routledge Education Studies series.

Do not cite without author's permission.

research and teaching activities. Both the Bundesländer and the national government then award further grants for additional projects. The most notable of these is the 'Excellence Initiative', launched in 2002, that provides large grants in particular research areas. Just under a third of the 150 or so of Germany's universities have won funding through this route, although nine of those have received considerably more than the rest (DFG 2012). Outside the Excellence Initiative, though, the research income for German universities seems to be relatively predictable and stable. Funding for research in the UK is almost entirely awarded on the basis of external evaluation and competition. Sectoral audits of research quality - currently called the Research Excellent Framework (REF) - were phased in from the 1980s and have dictated the share of state funding for research (Auranen \& Nieminen 2010). Other sources include disciplinary research councils, philanthropic bodies, and industry, by and large awarded on the basis of competitive application. In practice a relatively small number of more established universities dominates, particularly the 'golden triangle' of Oxford, Cambridge, and London (Harrison 2009). It is also notable that the proportion of private investment in higher education research in the UK is currently estimated at around 35\% (EI 2015), with 43\% of UK university funding (including tuition fees) overall coming from the private sector. In Germany the total figure is 15\% (OECD 2015).

\section{Governance}

In addition to being state funded, almost all German universities are publicly owned and governed, meaning that changes to their management structures and internal policies can be quite slow and bureaucratic. As Krücken and Meier (2006) have identified, the German Universität traditionally had no decision-making capacity in the same way as companies or other organisations. English universities, on the other hand, have an established history of being autonomous. This changed in the 1980s when state funding was reduced to encourage improvements in efficiency and orient universities more towards private sector (Walford 1991). This policy has been continued in various forms ever since accompanied by - as in Germany - major expansion in the size, authority and reach of the management and administrative staff (Shattock 2013; Blümel et al. 2010).

Both countries have also seen the emergence of external, disciplinary or pandisciplinary bodies which issue guidelines on the content and/or practices degree delivery. From the research perspective, Germany's Excellence Initiative and the UK's Research Excellence Framework, in addition to providing a way of allocating research funding, serve as publicly visible markers of quality and as such increase the sense of competition for status (and funding). This is bolstered by university rankings, which began to appear in both countries in the 1990s. However, in Germany they entered a largely unreceptive milieu because the established view was one of institutional parity across the country (Kosmütsky 2012). This is further undermined by the fact that there is no price differential and universities do not compete for students - they are already overstretched and students tend 
Working Paper: Draft Chapter for

International and Comparative Education: Contemporary Issues and Debates.

Bartram, B. (Ed) Routledge Education Studies series.

Do not cite without author's permission.

to study locally because there is no variation in quality or status. There has also been resistance to rankings in the academic profession, with some disciplines and universities refusing to submit the requisite data for analysis and publication (Kaube 2012). This is possible because of the universities' safe status as state organisations, and the professoriate's protected employment position as civil servants. The Excellence Initiative was intended to improve Germany's position in international rankings (which it has done), and while it has undermined the sense all universities are the same, it is more a case of a minority elite with the remainder being more or less equal.

The higher education sector in England/the UK has long been recognised as highly stratified (Teichler 2008), and league tables have simply reified and reinforced this. The perception that 'older is better' holds true because the longer a university is operational, the more advanced its research culture, expertise in applying for grants, and ability to attract seasoned academics and the highest attaining students. This has meant that the table positions are largely stable because the measured and perceived differences are reproduced year on year (Roberts \& Thompson 2007). All universities charge almost exactly the same for undergraduate degrees but in all other aspects, the sense of differential status is acute.

What all of this means in practice is that universities in Germany and England appear to be autonomous but this autonomy exists in different forms. German universities, because of heavy regulation, are somewhat protected from change (for better or worse) but the tenured academics at least have considerable freedom. In England the universities are heavily steered via external agencies and the way that the state-sponsored market distributes funding and students, and the freedom they have to make changes is very much dictated by external forces.

\section{From National to Local}

What do these differences in German and English higher education mean for students? Data collected in early 2012, just before tuition fees were raised to $£ 9000$ in England, provided some interesting insights.

\section{The Sample}

Thirteen undergraduate students - six German, seven English - across a range of ages, backgrounds, and disciplines were interviewed about how they saw and experienced their university contexts (Budd 2014). They were recruited from 'Mill University' in England and 'Feuerbach Universität' in Germany, research-intensive universities in regional towns, with 15-20,000 students and founded in the 1960s-70s. Both offer subjects across the disciplinary spectrum but lean towards STEM. However, Mill, in common with other English universities of this age and type, is well ranked, and operates a highly selective admissions system. Feuerbach, as with other German universities of its type, does not have exclusive entrance standards and is not considered one of the small elite. It should be noted here that the sample size, and the fact that all universities are somewhat unique, means that none of the findings below are generalisable. The point here is illustration, 
Working Paper: Draft Chapter for

International and Comparative Education: Contemporary Issues and Debates.

Bartram, B. (Ed) Routledge Education Studies series.

Do not cite without author's permission.

not extrapolation, and we will be looking at three interrelated areas - the broader context, teaching, and non-academic activities.

\section{Broader Context}

One area of distinction between the groups was in their views and use of rankings. None of the German students had considered them in their choice of university - perhaps unsurprising as Feuerbach was not of high status but they also knew little about them and viewed them sceptically. One German student had in fact begun his studies at one of the elite universities but transferred to Feuerbach at the end of the first year. He was aware of the status difference but saw rankings as 'nothing but hot air... before all the universities were seen as the same and I think they essentially still are'. The English students had all used rankings as a key factor in their choice of Mill again unsurprising given its high status - and were knowledgeable about the kinds of metrics used to compile them. They were slightly sceptical of some of those measures, but by and large did not question that rankings represented the reality of variations in quality and not seem to see that they induced competition

Tuition fees were another area where contrasts emerged. The English students mostly approved of fees and gave a range of justifications for their imposition, such as the poor economic climate and there was broad acceptance of a degree as 'an investment' in future earnings. They were mostly aware of the potential barrier to poorer students that fees might pose, but beyond this there were few arguments against them. The German group were almost exactly opposite, claiming that there was no guarantee of a good jobs, and they were all well-versed in arguments against fees while presenting few supporting arguments. An interesting point that emerged in the German accounts was that tuition fees were often seen as inappropriate because they made the university partly responsible for students' academic success. This connected with a key difference in how the groups saw the role of the university.

\section{Learning and Teaching}

Firstly, while both students cited responsibility for one's own learning as being a fundamental principle underpinning degree studies, this was more marked in the German students. Other than an introduction to module choices at the beginning of their degrees, they were very much on their own. Tuition fees, they claimed, undermined this independence because the university became obliged to help you rather than leave you to help yourself. For the English students the responsibility for doing well was still theirs, but the university was expected to facilitate this by providing good quality teaching as well as appropriate academic (as well as non-academic) facilities. The fact that they paid fees, though, was seen as a way of applying leverage to ensure that provision was suitable. Comparing the two universities, Mill was seen as a partner in actively engaging with students and improving their chances of doing well, while Feuerbach, was relatively passive; as one of the students saw it 'the university doesn't care if you fail'. 
Do not cite without author's permission.

This emerging distinction in the role of the university towards students also featured in way that degrees were taught. The German group generally referred to two teaching formats, lectures and smaller classes. Most experienced both, and two students mentioned smaller, graduate-student led sessions, but some courses were almost entirely taught in 90-minute lectures. The English students, on the other hand, named a far greater range, with lectures (of 45 minutes), seminars, tutorials, and practical workshops. The German emphasis on lectures as a means of delivery, as well as limited access to academics and interactions that did occur only being conducted in very formal terms, contributed to a clear divide between academics and students. Some of this might be connected to the fact that the university was operating beyond its capacity, something that all of the Feuerbach students mentioned. At Mill, in addition to each student having a named tutor who was responsible for their academic wellbeing, students were often encouraged to address their teaching staff by their first names, and there was an 'open door policy' where they could approach academics directly. It would have been possible in some subjects at Feuerbach to complete almost the entire degree without having a conversation with an academic, while at Mill this would have been out of the question.

\section{Non-academic Activities}

A third area of major difference in the participants' accounts was in the way that the two groups talked about the non-academic aspect of a degree. Mill, in common with other English/UK universities, had an extensive range of sporting and other activities that students were expected to engage with. Many of the English participants referred to the importance of these not only for fun and relaxation, but also as a way of improving one's CV. As one of the students explained, 'they drill this into us...work places are asking what activities you do and what interests you have because they don't want people that are just academic.' Employability was a pervasive topic, with the same logic applied to other aspects such as mixing with international students 'because we'll be working internationally' and work experience 'some companies are only accepting people that have been on placements.' This connected with a strong sense across the English group of a need to optimise one's combination of academic and non-academic performance in order to be successful on a highly competitive labour graduate market. The status of the university was also seen to be a contributing factor, while for the Germans it was considered irrelevant, and research has shown that both groups may have been right about their own national contexts (Leuze 2011). The German students talked about international students being good to have as they brought different perspectives to discussions, but there was no other value associated with these or internships even though nearly all German students do one as part of their degree. Feuerbach had sports facilities and some social groups, but they were far less extensive and prominent, and this contributed to the sense that the university was less central in its students' lives than Mill was. Feuerbach by and large provided learning opportunities which the students could to choose to avail themselves of (or not), while Mill was 
Working Paper: Draft Chapter for

International and Comparative Education: Contemporary Issues and Debates.

Bartram, B. (Ed) Routledge Education Studies series.

Do not cite without author's permission.

somewhere that students spent a great deal of their academic as well as nonacademic time.

\section{Conclusion}

What can we learn from this? Starting from the local and working our way back up, we can see that university can 'feel' quite different in different places. It is important to note here that the differences have been highlighted, and there were also similarities in their descriptions such as good (and bad) lecturers or that criticality and academic freedom underpinned university activity as a whole. We can see, at the local level, though, how Mill aggressively promotes the employability agenda, something that is driven by tuition fees and university rankings, or that Feuerbach took less of an active role in its students' degrees and lives than Mill did. This is likely to differ at other universities in each country, but it also connects with the higher education policies and cultures in each country.

At the national, the rise in student numbers featured for both groups, but for the Germans it came through in their sense that the university was overflowing (although they saw this as a local, not national issue), while for the English students the job market for graduates was heavily congested. Tuition fees and rankings came through in different ways, with the Germans being more opposed to the former and sceptical and/or lacking awareness of the latter. It should also be noted that much has been made of the fact that tuition fees frame students as customer, as passive and demanding customers (Tight 2013). The English students did expect more from their university, but this seems more due to the national/local culture of what a university does. Tuition fees may change the way that students see a degree, but it is not the only contributing factor.

Through this we can begin to identify how global trends become visible not only at the national level but also at the local, and how they might manifest themselves differently between and across those levels. In some senses we can see that Mill University and the English students have been influenced more greatly by the logic of the knowledge economy, while those at Feuerbach were more insulated from it. Time, space and meaning may be coming closer together in globalisation, but the meanings can still be quite different.

\section{Discussion Questions}

- Is globalisation both a social phenomenon and a political project?

- Some have described globalisation as leading towards a worldwide convergence. How might you justify or refute this position?

- Can you see neoliberal approaches in other areas of education or in other sectors? How appropriate do you feel this approach is there?

- What kinds of things might influence the experience of being at university, between university departments, between universities, and between countries? 
Working Paper: Draft Chapter for

International and Comparative Education: Contemporary Issues and Debates.

Bartram, B. (Ed) Routledge Education Studies series.

\section{Suggested Research Projects}

Do not cite without author's permission.

- Which supranational organisations influence university policy, and how?

- How do students see and use university rankings?

- How do domestic and international students experience the same course/university/country?

\section{Additional/Recommended Reading}

Santos, B. de S., 2006. Globalizations. Theory, Culture E Society, 23(2-3), pp.393-399.

Ravinet, P., 2008. From Voluntary Participation to Monitored Coordination: why European countries feel increasingly bound by their commitment to the Bologna Process. European Journal of Education, 43(3), pp.353-367.

\section{References}

Alexander, J.C., 2005. "Globalization" as Collective Representation: The New Dream of a Cosmopolitan Civil Sphere. International Journal of Politics, Culture and Society, 19(May 2006), pp.81-90.

Ashwin, P., 2015. Missionary zeal: some problems with the rhetoric, vision and approach of the AHELO project. European Journal of Higher Education, 5(4), pp.437-444.

Auranen, O. \& Nieminen, M., 2010. University research funding and publication performance-An international comparison. Research Policy, 39(6), pp.822-834.

Bloch, R., 2009. Flexible Studierende? Studienreform und studentische Praxis., Leipzig: Akademische Verlagsanstalt.

Blümel, A. et al., 2010. Restrukturierung statt Expansion: Entwicklung im Bereich des nichtwissenschaftlichen Personals an Deutschen Hochschulen. Die Hochschule, 20(2), p.p.154-172.

Brown, P., Lauder, H. \& Ashton, D., 2011. The Global Auction: The Broken Promises of Education, Jobs, and Incomes, Oxford: Oxford University Press.

Buchanan, A. \& Keohane, R.O., 2011. Precommitment Regimes for Intervention: Supplementing the Security Council. Ethics \& International Affairs, 25(1), pp.41-63.

Budd, R., 2014. Students as Neo-Institutional Actors: A Comparative Case Study of How German and English Undergraduates Understand, Experience and Negotiate Higher Education. Bristol: University of Bristol.

Calhoun, C., 2006. The University and the Public Good. Thesis, 84, pp.7-43.

Codd, J., 2005. Academic Freedom and the Commodification of Knowledge in the Modern University. Learning for Democracy, 1(1), pp.69-87.

Corbett, A., 2006. Higher Education as a Form of European Integration : How Novel is the Bologna Process?, Oslo.

Croché, S. \& Charlier, J.-émile, 2012. Normative influence of the Bologna Process on French-speaking African universities. Globalisation, Societies and Education, 10(4), pp.457-472.

Dale, R., 2005. Globalisation, Knowledge Economy and Comparative Education. Comparative Education, 41(2), pp.117-149. 
Working Paper: Draft Chapter for

International and Comparative Education: Contemporary Issues and Debates.

Bartram, B. (Ed) Routledge Education Studies series.

Do not cite without author's permission.

DFG, 2012. Entscheidungen in der Exzellenzinitiative (15. Juni 2012), Bonn.

Douglass, J.A., 2005. ALL GLOBALIZATION IS LOCAL : COUNTERVAILING FORCES AND THE INFLUENCE ON HIGHER EDUCATION MARKETS, Berkeley.

Dreher, A., Sturm, J.-E. \& Vreeland, J.R., 2015. Politics and IMF Conditionality. Journal of Conflict Resolution, 59(1), pp.120-148.

EHEA, 2016. The European Higher Education and Bologna Process. EHEA and Bologna Process Website.

EI, 2015. What is the relationship between public and private investment in science, research and innovation?, London.

European Commission, 2014. OTH-LISBON STRATEGY - The Lisbon Strategy for growth and jobs. CORDIS - Community Research and Development Information Service. Available at:

http://cordis.europa.eu/programme/rcn/843_en.html.

Fried, J., Glass, A. \& Baumgartl, B., 2006. Summary of an Extended Comparative Analysis on European Private Higher Education1. Higher Education in Europe, 31(1), pp.3-9.

Harrison, M., 2009. Does high-quality research require "critical mass"? In D. Pontikakis, D. Kyriakou, \& R. van Bavel, eds. The question of RED specialisation: perspectives and policy implications. Luxembourg: Office for Official Publications of the European Communities, pp. 53-55.

Hazelkorn, E., 2008. Learning to Live with League Tables and Ranking: The Experience of Institutional Leaders. Higher Education Policy, 21, pp.193215.

HEFCE, 2016. Register of Providers. Higher Education Funding Counci for England. Available at: http://www.hefce.ac.uk/reg/register/search/Overview.

Hoschschulrektorkonferenz, 2016. Hoschschulkompass. Hochschulkompass. Available at: http://www.hochschulkompass.de/.

Kaube, J., 2012. Widerstand gegen den Unfug des "Rankings." Frankfurter Allgemeine Zeitung, p.5. Available at:

http://www.faz.net/aktuell/feuilleton/forschung-und-lehre/uniranglisten-widerstand-gegen-den-unfug-des-rankings-11863221.html.

King, R., 2011. Globalisation and Higher Education. In J. Brennan \& T. Shah, eds. Higher Education and Society in Changing Times: looking back and looking forward. Milton Keynes: CHERI; The Open University, pp. 24-35.

Kosmütsky, A., 2012. Between Mission and Market Position: Empirical findings on mission statements of German Higher Education Institutions. Tertiary Education and Management, 18(1), pp.55-77.

Kotz, D.M., 2009. The Financial and Economic Crisis of 2008: A Systemic Crisis of Neoliberal Capitalism. Review of Radical Political Economics, 41(3), pp.305-317.

Krücken, G. \& Meier, F., 2006. Turning the University into an Organizational Actor. In G. S. Drori, J. W. Meyer, \& H. Hwang, eds. Globalization and Organization: World Society and Organizational Change. Oxford: Oxford University Press, pp. 241-257. 
Working Paper: Draft Chapter for

International and Comparative Education: Contemporary Issues and Debates.

Bartram, B. (Ed) Routledge Education Studies series.

Do not cite without author's permission.

Leuze, K., 2011. How structure signals status: institutional stratification and the transition from higher education to work in Germany and Britain. Journal of Education and Work, 24(5), pp.449-475.

Marginson, S., 2011. Imagining the Global. In R. King, S. Marginson, \& R. Naidoo, eds. Handbook On Globalization And Higher Education. Cheltenham: Edward Elgar Publishing, pp. 10-39.

Marginson, S., 2006. Investment in the self: The government of student financing in Australia. Studies in Higher Education, 22(2), pp.37-41.

Meyer, H.-D. \& Benavot, A., 2015. PISA and Globalization of Education Governance: some puzzles and problems. In H.-D. Meyer \& A. Benavot, eds. PISA, Power, and Policy: the emergence of global educational governance. Oxford: Symposium Books, pp. 7-26.

Mountford, J.F., 1966. British Universities, Oxford: Oxford University Press.

Neary, M. \& Saunders, G., 2016. Student as Producer and the Politics of Abolition Making a New Form of Dissident Institution? Critical Education, 7(5), pp.1-23.

OECD, 2000. Education at a Glance 2000: OECD Indicators, OECD Publishing. OECD, 2015. Education at a Glance 2015 - OECD Indicators, OECD Publishing.

Pritchard, R., 2006. Trends in the Restructuring of German Universities. Comparative Education Review, 50(1), pp.90-112.

Roberts, D. \& Thompson, L., 2007. Reputation Management for Universities: University League Tables and The impact on student recruitment,

Robertson, S.L., 2009. 'Education, Knowledge and Innovation in the Global Economy: Challenges and Future Directions'. In Keynote Address to Launch of Research Centres, VIA University College, Aarhus, Denmark, 6th March, 2009. Aarhus.

Robertson, S.L., 2012. Researching Global Education Policy: Angles In/On/Out .... In A. Verger, M. Novelli, \& H. Altinyelken, eds. Global Education Policy and International Development: New Agendas Issues and Practices. New York: Continuum Books, pp. 1-21.

Shattock, M., 2013. University Governance, Leadership and Management in a Decade of Diversification and Uncertainty. Higher Education Quarterly, pp.1-17.

Shore, C., 2010. Beyond the multiversity: neoliberalism and the rise of the schizophrenic university. Social Anthropology, 1, pp.15-29.

Teichler, U., 2008. Diversification? Trends and explanations of the shape and size of higher education. Higher Education, 56, pp.349-379.

Tight, M., 2013. Students: Customers, Clients or Pawns? Higher Education Policy, 26(291-307).

Tilak, J.B.G., 2015. Global Trends in Funding Higher Education. International Higher Education, e-prints(Marketization and Economic Themes), pp.5-6.

Walford, G., 1991. The changing relationship between government and higher education in Britain. In G. Neave \& F. van Vught, eds. Prometheus Bound: The Changing Relationship Between Government and Higher Education in Western Europe. Oxford: Pergamon, pp. 165-183.

Williams, R. \& Cochrane, A., 2010. The role of higher education in social and 
Working Paper: Draft Chapter for

International and Comparative Education: Contemporary Issues and Debates.

Bartram, B. (Ed) Routledge Education Studies series.

Do not cite without author's permission.

cultural transformation. 